\title{
QUANDO O LÍRICO INTERROMPE O ÉPICO: ESCURO, DE ANA LUÍSA AMARAL
}

\author{
Maria Irene Ramalho \\ Faculdade de Letras da Universidade de Coimbra
}

Em 7 de Março passado tive o gosto de apresentar Ara (2013) em Coimbra. Nessa altura, repeti o que tinha escrito para a badana dessa edição da Sextante: "Ara é o mais teórico dos escritos poéticos de Ana Luísa Amaral". Expliquei-me, creio que com êxito, durante a apresentação desse livro. Começarei agora por dizer, de Escuro, que se trata do poema mais modernista de Ana Luísa Amaral. Tal como vários longos poemas-feitos-de-poemas do modernismo ocidental - e tenho

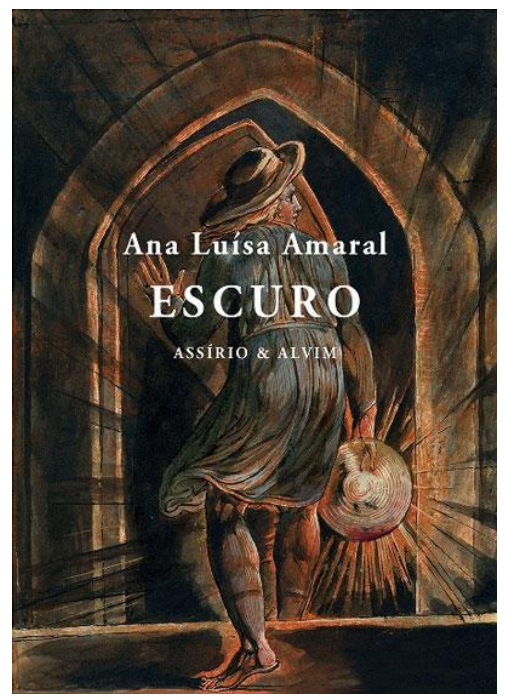
particularmente em mente The Bridge, de Hart Crane (1930), e Mensagem, de Fernando Pessoa (1934), este último, como veremos, bem presente neste livro -, Escuro é também, como estes, e como diria Ezra Pound, um poema-que-inclui-história. Mas, enquanto esta é a célebre definição poundiana de epopeia ("a poem including history"), eu leio estes poemas modernistas como ensaiando magistralmente uma mútua interrupção poética do épico pelo lírico e do lírico pelo épico. Um processo que muito deve também às relações entre a poesia, o mito, a profecia e a utopia. Eu atrever-me-ia até a dizer que Escuro, de uma autora que tão bem sabe escrever do avesso (e o conceito é repetido três vezes em três diferentes poemas deste livro), pode bem ser lido como o avesso de poemas já antes ambiguamente celebratórios da nação enquanto utopia 
possível, como, por exemplo, os modernistas Mensagem e The Bridge. Se nem The Bridge nem Crane são personagens de Escuro, Mensagem e Pessoa povoam-no do princípio ao fim.

Não temos, em Escuro, o interrogado "Grão Cataio" de Crane e, muito menos, a esquiva "Hora" pessoana. Temos, no entanto, nos dois últimos poemas a encerrar o livro, uma "outra fala" que desejaria dizer do amor, do futuro e da infinita possibilidade de paz no tempo. Mas não diz nada disso, apenas, como compete à poesia, o imagina - e o imagina em evidente triste desalento. O primeiro dos dois poemas, "Amar em futuro", projecta esse possível futuro no condicional: "Se daqui a mil anos ... a paz seria toda nesse mundo ... a paz seria toda". O poema termina, porém, em ameaça, que é a que vivemos todos nós hoje no século XXI, sem saber de que lado da explosão tectónica nos encontraremos: "A paz seria toda. Só a placa movendo-se/ tão lenta, ao longo desse tempo, passado já além de três mil anos. Explosão ou terramoto a ameaçar -". O segundo poema, o que verdadeiramente encerra o volume, intitula-se "O drama em gente: a outra fala", e é o avesso de poema anterior, "O drama em gente", na p. 39, o qual, esse sim, canta o pessoano drama-em-gente, o daquele poeta que se fez muitos num só, aquele do desassossego, a quem um dia doeram a cabeça e o universo - o multímodo Fernando Pessoa, esse cuja grandeza ameaça deixar "silente" a voz poética. No entanto, o poema que fecha a sequência de Escuro é uma "outra fala", aquela que este poema feito de poemas e evocador de poetas magnificamente apropria para si e imaginativamente transforma.

Escuro é um poema que para si reinventa poetas e a sua poesia, uns e outros interruptivos da história. Não se trata de re-escrita, antes de re-visão no sentido que lhe deu, em contexto e com objectivos diferentes, Adrienne Rich no célebre ensaio feminista, "When We Dead Awaken. Writing as Re-vision" (1972). Em Escuro, a poeta re-vê a história de Portugal e da Europa e mostra como essa história se projectou no mundo por meio de guerras supostamente em busca da utopia da paz, como a que foi cantando a imaginação de poetas. Camões, por exemplo, cujos Lusíadas são re-vistos em Pessoa e este em Ana Luísa Amaral.

Por isso digo que Escuro é um poema-feito-de-poemas. Ou, mais bem dito, um poema-feito-de-poetas. Comecemos pelo motivo da capa, a gravura-frontisfício de Jerusalem (1804-1820) um dos poemas proféticos de William Blake (1757-1827). A imagem do poeta como guarda-nocturno, uma concepção do poeta realizada em gravura muito provavelmente pela sua mulher, Catherine Boucher, a iluminar a negridão da noite com a sua luz, serve à maravilha a poeta-do-escuro que Ana Luísa Amaral se representa neste livro. Um escuro que é um escuro-outro que não o da noite, como sugere a epígrafe retirada de San Juan de la Cruz (1542-1591): a poeta não tem outra luz senão a que arde no coração da poesia - e que é a imaginação. Mais do que o místico espanhol do século XVI, porém, o visionário inglês do virar do século XVIII, William Blake, preside de cer- 
to modo a este novo livro de Ana Luísa Amaral. Além do já mencionado frontispício, há a outra epígrafe, retirada de América a Prophecy (1793), o poema em que Blake profetiza a libertação da tirania e a emancipação dos povos, que a Revolução Americana para ele simbolizou. Ou quis que simbolizasse. Ao texto escolhido para epígrafe por Ana Luísa Amaral "The morning comes, the night decays, the watchmen leave their station" - chamou David Erdman "Blake's poetic paraphrase of the Declaration of Independence". Concordo; mas, então, como se explica a "vergonha" que sente o poeta de America a Prophecy no final do "Prelúdio" de que fez anteceder o poema? Lembro o passo respectivo, em que o Bardo austero se reduz ao silêncio, destrói a harpa e se afasta em lúgubres lamentos:

The stern Bard ceas'd, asham'd of his own song; enrag'd he swung His harp aloft sounding, then dash'd its shining frame against A ruin'd pillar in glitt'ring fragments; silent he turn'd away, And wander'd down the vales of Kent in sick and drear lamentings.

O grande especialista da obra de Blake já mencionado, David Erdman, sugere que esse fragmento tem implicações autobiográficas. É muito provável. Mas o que entendo dessa poética vergonha, através das antenas retro-imaginativas de Ana Luísa Amaral, é que o bardo blakiano tem, profeticamente, pejo da profecia de emancipação revolucionária que está prestes a proferir. Ou não tivesse ele ilustrado Narrative of a Five Year's Expedition against the Revolted Negroes of Surinam (1796), do Capitão John Gabriel Stedman, ao mesmo tempo que subvertia a mensagem de supremacia branca que lhe subjaz. Blake ter-se-á logo apercebido das "menos nobres razões para se declarar a independência", recentemente explicadas por historiadores como Peter Linebaugh e Marcus Rediker (The Many-Headed Hydra, 2000; 2013). O discurso triunfante da construção da nação com vocação de império, em que a revolucionária "América" de Blake se viria a tornar, é desmontado pela desconstrução do discurso da história imperial portuguesa em Escuro de Ana Luísa Amaral.

Será neste contexto que deveremos perguntar de que forma dialogam estas epígrafes com o poema e os seus leitores. Julgo saber que a poeta hesitou em intitular este livro "Por que outra noite trocaram o meu escuro?" - o título da parte central do livro, englobando 16 poemas num total de vinte. Um estudo mais aprofundado deste luminoso Escuro de Ana Luísa Amaral teria de debruçar-se com demora e cuidado sobre as diferentes imagens de escuridão (como escuro e noite), bem como de luz e fogo (como o lume que literal e etimologicamente ilumina).

Escuro estrutura-se, muito simetricamente, com dois poemas a abrir, ou introdutórios, e dois poemas a fechar, ou conclusivos. Dos dois últimos falei já um pouco: dizem da voz outra da poeta que percorreu a poesia ocidental deslumbrada, mas sem se deixar seduzir totalmente por ela. Era outra fala, ou outra coisa, em outra voz, o que ela desejava. Entender-se-á melhor se ela realiza ou não o seu desejo, voltando ao princípio, à secção intitulada "Claro-Escuro". No primeiro poema, "Das mais puras 
memórias: ou de lumes", leio eu a construção do sujeito poético. Primeiro, num tempo luminoso, o de ontem, com recurso à memória da inocência da infância; depois, num tempo brutal, o de hoje, um tempo de "povos sem nome, sem luz", um tempo de "vidas cortadas". E, no entanto, os tempos coabitam, o da "luz", o da "pura alegria", e o da "violência de ser". Como não pensar no Blake da inocência e da experiência, cantares escritos afinal, como hoje bem sabemos, em simultâneo?

O segundo poema introdutório, "Entre mitos: ou parábola", é de facto uma parábola do primeiro colonialismo europeu, esse que chegou a África, às "margens do Nilo", e devastou culturas e saberes ancestrais, a viverem no "centro do seu tempo", para as espoliar e fazer suas. Leia-se o começo do poema:

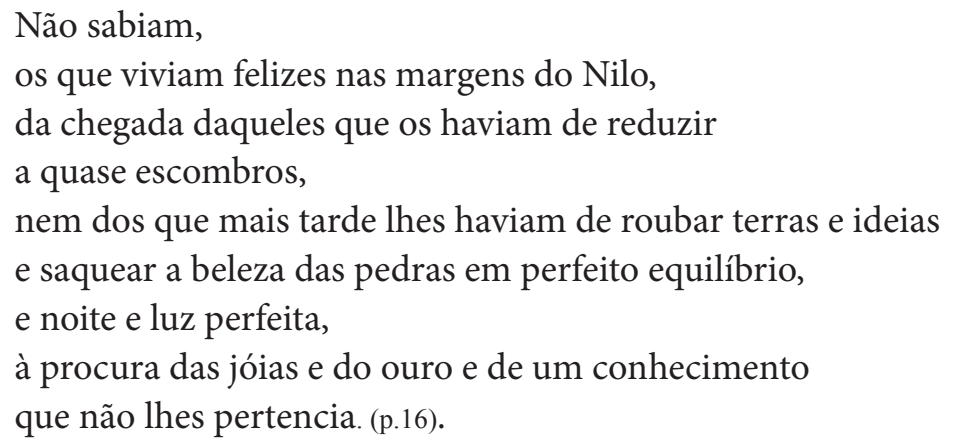

O corpo central do longo poema-feito-de-poemas, Escuro, os dezasseis poemas a que já me referi acima, reinventam, no poético, a história de um Ocidente expansionista e imperial com rosto português. E digo reinventam, ponderando bem o que digo. A reinvenção da nossa história de séculos por esta nossa poeta do século XXI passa por uma utopia, em "outras vozes", que se localiza, por assim dizer retroactivamente, no passado pré-colonial: "Não eleger nem mar, nem horizonte./ E embarcar sem mapa até ao fim/do escuro". Esse escuro de onde paradoxalmente nasceria a luz.

Pelos poemas centrais do livro passa uma galeria de figuras da nossa história pela poeta reinventadas com fina ironia. O rei lavrador/ trovador, em cujo belo sonho delicadamente se insinua o resultado colonial das naus ("O sonho"); a Rainha Santa com um cheiro "adocicado" de milagres ("O tempo dos dragões e algumas rosas"); Inês e Constança (as mulheres de D. Pedro I), cúmplices na amizade feminina, ainda em lírica inocência dos crimes de quem as irá desgraçar ("No sossego dos frutos"); o infante D. Henrique, cheio de dúvidas sobre o que terá ou não realizado (“O promontório"); a Ínclita Geração virada do "avesso" pela mãe inglesa, Filipa de Lencastre (“A cerimónia”); Fernão Lopes a reinventar reis como D. Pedro I de Portugal ("O retrato"); o pessoano nevoeiro a recontar o mito de D. Sebastião com o Infante Santo em pano-de-fundo ("O nevoeiro"); Mariana Alcoforado, figura central para a reinvenção da literatura portuguesa nas Novas Cartas (“A carta”); o Adamastor, ainda "por inventar", a sugerir que a história dos portugueses achamentos não está ainda toda contada ("Adamastor"); o menino de sua mãe de Pessoa, ansiando por dormir, em evocação oblíqua do dormeur du vale, de Rimbaud (“A voz"); e uma Europa 
que, ao contrário da Mensagem de Pessoa, nada fita afinal, e nem sequer cotovelos tem em que se apoiar ("Europa [poema 2])".

Escuro é um poema em que Ana Luísa Amaral revisita a poesia a partir dos poetas que poeticamente escreveram a história de si próprios, como San Juan de La Cruz, ou a história da história, como William Blake, ou a história da poesia-feita-história, como Fernando Pessoa.

A lucidez de Escuro canta a portuguesa história nossa, que sempre na escola nos deixaram por contar.

\section{REFERÊNCIA BIBLIOGRÁFICA}

AMARAL, Ana Luíza. Escuro. Lisboa: Assírio \& Alvim, 2014.

Recebido para publicação em 14/05/2014

Aprovado em 24/09/2014 